www.nature.com/pj

\title{
Synthesis of branched poly(lactic acid) bearing a castor oil core and its plasticization effect on poly(lactic acid)
}

\author{
Takashi Tsujimoto, Yoshimi Haza, Yinan Yin and Hiroshi Uyama
}

Branched poly(lactic acid) was synthesized by ring-opening polymerization of lactide using castor oil as an initiator. The structure of the branched polymer was confirmed by ${ }^{1} \mathrm{H}$ nuclear magnetic resonance spectroscopy. The molecular weight of the branched polymer increased linearly as a function of the feed ratio of lactide and castor oil. The thermal properties of the branched polymer were evaluated using differential scanning calorimetry and were compared with those of linear poly(L-lactic acid) (PLLA). A blended film of the branched polymer and PLLA was prepared by hot pressing at $175^{\circ} \mathrm{C}$. A content of 5 wt\% of the branched polymer was sufficient to increase the strain at break. Thermomechanical analysis of the blended film revealed a decrease in the initial elastic modulus with addition of the branched polymer. The thermal and dynamic mechanical properties of the film were examined, and the crystalline morphology of the film was examined by polarized light microscopy.

Polymer Journal (2011) 43, 425-430; doi:10.1038/pj.2011.3; published online 9 February 2011

Keywords: biomass plastic; branched polymer; castor oil; plasticizer; poly(lactic acid)

\section{INTRODUCTION}

The use of biomass as a polymer precursor is of increasing interest because of its potential to reduce greenhouse gas emissions and to contribute to global sustainability by preventing the depletion of scarce fossil resources. ${ }^{1,2}$ The development and commercialization of plastics from renewable resources could be a solution to problems concerning energy resources and the environment.

Among bioresources, natural oils are expected to be an ideal alternative chemical feedstock because oils derived from both plant and animal sources are found in abundance in nature. Inexpensive triglyceride plant oils have been used for the production of valuable resins. ${ }^{3}$ Besides common plant oils, such as soybean and palm oils, castor oil has also been used in the production of resins. Castor oil is mainly composed of ricinoleic acid bearing a secondary hydroxyl group and glycerol. ${ }^{4}$ It is produced primarily in India, and is classified as an inedible oil because of its nauseant properties. Various industrial applications of castor oil and its derivatives have been developed. Castor oil is used as a polyol for polyurethanes, which have wide usage in the automotive, building and furniture industries. ${ }^{5,6}$ Sebacic acid and 11-aminoundecanoic acid are industrially produced by the pyrolysis of castor oil (and the derivatization described below). These two compounds are the monomers of bio-based nylon 610 and 11, respectively. Functional polymers made from castor oil and ricinoleic acid derivatives have been reported. ${ }^{4,7-10}$ Maleated castor oil has been prepared and used in the synthesis of plastic foams by radical copolymerization of maleated castor oil and styrene. ${ }^{7}$ The lipase- catalyzed polymerization of ricinoleic acid methyl ester produced a corresponding polymer with a high-molecular weight, which was applied to a thermosetting elastomer. ${ }^{8}$ Copolyesters of lactic acid and ricinoleic acid have been prepared and their thermal properties examined. ${ }^{9}$ The copolymerization of lactic acid and castor oil using phosphoric acid as a catalyst has also been reported. ${ }^{10}$

Poly(L-lactic acid) (PLLA) is one of the most common commercially available bio-based polymers. ${ }^{1-13}$ PLLA is a thermoplastic aliphatic polyester derived from inexpensive renewable resources, such as corn and sugar beets. PLLA is fully biodegradable and has good mechanical properties, including a high tensile strength. At present, Nature Works (Minnetonka, MN, USA) produces PLLA through a combination of biological and chemical processes using corn as a raw material. PLLA offers great promise in a wide range of commodity applications. However, the industrial applications of PLLA are limited at present. PLLA has several undesirable characteristics, such as high brittleness, low impact strength, low heat resistance, low crystallization rate in injection molding and a low gas barrier. The high brittleness and low impact strength are because of the large crystal of PLLA.

The synthesis of various branched and hyperbranched poly(lactic acid)s has been reported. ${ }^{14-20}$ The branched polymers were produced by ring-opening polymerization of lactide using initiators with more than three hydroxyl groups. Some of the typical initiators were pentaerythritol, dipentaerythritol, myo-inositol, glycerol and polyglycidol. ${ }^{14-18}$ The structural effects of branched and linear poly(lactic acid)s 
on physical properties have been examined. ${ }^{18}$ The hyperbranched polymers were obtained by the copolymerization of lactide with glycidol or 2,2-bis(hydroxymethyl)butyric acid using tin(II) octanoate as a catalyst. ${ }^{19,20}$

Considerable efforts have been made to enhance the flexibility of PLLA, and thereby overcome its inherent brittleness by blending PLLA with low-molecular-weight plasticizers or other polymers. Various compounds have thus far been used to achieve good plasticization effects in PLLA. These include citrates, poly(ethylene glycol), bis(2ethylhexyl) adipate, glyceryl triacetate, triacetin, oligomeric poly(1,3butylene glycol adipate), diethyl bishydroxymethyl malonate, oligomers of citrate and poly(propylene glycol) $)^{21-27}$ The plasticization of PLLA by these compounds often resulted in a substantial decrease in the crystallinity of PLLA, which causes a lowering of heat resistance and tensile strength. ${ }^{25}$ In some plasticizers with low-molecular weight, the plasticization effect became lower over time because of the migration or volatilization of the plasticizer. Thus, the need for an oligomeric or polymeric high-performance PLLA plasticizer has increased in recent years.

In this study, we report the synthesis of a branched poly(lactic acid) bearing a castor oil core and its application as a PLLA plasticizer. The addition of only $5 \mathrm{wt} \%$ of the branched polymer resulted in a moderate plasticization effect in PLLA without lowering its tensile strength. This study is highly significant in that it provides a synthetic scheme for creating a bio-based additive consisting of poly(lactic acid) and castor oil for the plasticization of PLLA.

\section{EXPERIMENTAL PROCEDURE}

\section{Materials}

Castor oil was obtained from Wako Pure Chemical Industries, Osaka, Japan. L-lactide (LLA) and D,L-lactide were purchased from Tokyo Kasei, Tokyo, Japan, and used without further purification. PLLA was obtained from Nature Works (product 4032D). Other reagents and solvents were commercially available and used as received.

\section{Measurements}

${ }^{1} \mathrm{H}$ nuclear magnetic resonance spectra were recorded on a Bruker DPX-400 instrument (Billerica, Bruker, MA, USA). Size-exclusion chromatographic analysis was carried out using a TOSOH SC8020 apparatus with a refractive index detector at $40^{\circ} \mathrm{C}$ under the following conditions: TOSOH TSKgel $\mathrm{G} 3000 \mathrm{H}_{\mathrm{HR}}$ column and chloroform eluent at a flow rate of $1.0 \mathrm{ml} \mathrm{min}^{-1}$ (Tosoh, Tokyo, Japan). The calibration curve was obtained using polystyrene standards.

Differential scanning calorimetry (DSC) analysis was performed using a SEIKO DSC6020 apparatus in a nitrogen flow rate of $30 \mathrm{ml} \mathrm{min}^{-1}$. In the first heating run, the sample was heated from 20 to $200^{\circ} \mathrm{C}$ at a heating rate of $10{ }^{\circ} \mathrm{C} \mathrm{min}^{-1}$ (Seiko Instruments, Chiba, Japan). After annealing at $20{ }^{\circ} \mathrm{C}$ for $5 \mathrm{~min}$, the sample was cooled from 200 to $-50^{\circ} \mathrm{C}$ at a cooling rate of $10^{\circ} \mathrm{C} \mathrm{min}^{-1}$. In the second heating run, the sample was heated from -50 to $200^{\circ} \mathrm{C}$ at a heating rate of $10^{\circ} \mathrm{C} \mathrm{min}^{-1}$ after being held at $-50^{\circ} \mathrm{C}$ for $5 \mathrm{~min}$. Dynamic mechanical analysis was carried out using a SEIKO DMS 6100 apparatus with a frequency of $1 \mathrm{~Hz}$. The run was conducted at a heating rate of $3{ }^{\circ} \mathrm{Cmin}^{-1}$ between -50 and $190^{\circ} \mathrm{C}$. Thermomechanical analysis was conducted using a SEIKO TMA/SS 6100 at a cross-head speed of $50 \mu \mathrm{m} \mathrm{min}^{-1}$ at $25^{\circ} \mathrm{C}$ to measure the initial elastic modulus. The specimen size was $10 \times 3 \times 0.1 \mathrm{~mm}$.

Mechanical properties were measured using a Shimadzu EZ Graph tensile tester (Shimadzu, Kyoto, Japan). Measurement was carried out at a cross-head speed of $5 \mathrm{~mm} \mathrm{~min}^{-1}$ at room temperature. The specimen size was $10 \times 5 \times 0.1 \mathrm{~mm}$. Polarization microscopic analysis was carried out using an OLYMPUS BX51 microscope (Olympus, Tokyo, Japan) equipped with an Imoto MHS-2000 heating stage (Imoto Machinery, Kyoto, Japan). The sample was placed on a glass slide, melted at $185^{\circ} \mathrm{C}$ on a heating stage and subsequently cooled at room temperature.

\section{Synthesis of branched poly(lactic acid)}

The synthesis procedure with the feed ratio of LLA to castor oil of 50 was carried out as follows: a mixture of LLA $(0.72 \mathrm{~g}, 5.0 \mathrm{mmol})$, castor oil $(0.093 \mathrm{~g}$, $0.10 \mathrm{mmol})$ and tin(II) octanoate $(0.050 \mathrm{~g}, 0.12 \mathrm{mmol})$ was kept at $130^{\circ} \mathrm{C}$ in argon atmosphere with gentle stirring. After $24 \mathrm{~h}$, the mixture was dissolved in $3 \mathrm{ml}$ of chloroform, and the solution was poured into $30 \mathrm{ml}$ of methanol. The precipitated polymeric material was collected by centrifugation and dried in vacuo to yield $0.51 \mathrm{~g}$ of the polymer ( $63 \%$ yield).

\section{Film preparation of PLLA/branched poly(lactic acid) blend}

A mixture of PLLA $(0.95 \mathrm{~g})$ and branched poly(lactic acid) $(0.050 \mathrm{~g})$ was dissolved in $5 \mathrm{ml}$ of chloroform at room temperature with gentle stirring. After $12 \mathrm{~h}$, the solution was cast on a glass plate, and the solvent was allowed to evaporate for $12 \mathrm{~h}$ at room temperature. The solid obtained was heated at $175^{\circ} \mathrm{C}$ for $20 \mathrm{~min}$ and hot pressed at the same temperature under a pressure of $5 \mathrm{MPa}$ for $10 \mathrm{~min}$, followed by rapid quenching at $0{ }^{\circ} \mathrm{C}$, producing a blended film with a thickness of $100 \mu \mathrm{m}$.

\section{RESULTS AND DISCUSSION}

Synthesis of branched poly(lactic acid)

It is well known that ring-opening polymerization of lactide using tin(II) octanoate initiates at a hydroxyl group. ${ }^{19,20,28}$ In this study, castor oil, which has three secondary hydroxyl groups, was used as an initiator for the polymerization of lactide. LLA or D,L-lactide was polymerized using tin(II) octanoate in bulk. Nearly all of the monomer was consumed during polymerization. Using LLA as the monomer, the resulting polymer was isolated by reprecipitation using chloroform and methanol as the solvent and antisolvent, respectively. The polymer was isolated in moderate yields. Some of the product might have been lost during the purification procedure because of high solubility of the oligomeric product in methanol.

The structure of branched PLLA was confirmed by ${ }^{1} \mathrm{H}$ nuclear magnetic resonance spectroscopy (Figure 1). The peak (peak d) due to the $\alpha$-methine proton of the hydroxyl group of castor oil at $\delta 3.6$ was not observed, but a peak (peak D) ascribed to the $\alpha$-methine proton of the esterified moiety of castor oil was observed at $\delta 4.9$, in addition to peaks $\mathrm{C}, \mathrm{E}$ and $\mathrm{J}$ due to methyl and methine protons of poly(lactic acid). A peak E, ascribed to the $\alpha$-methine proton of the terminal hydroxyl group of poly(lactic acid), was observed at $\delta$ 4.4. The assignment of other peaks is shown in Figure 1. The average degree of polymerization of the branched chain was estimated from the ratio of the integrated areas under peaks B, C, E and N. The degree of polymerization value estimated by ${ }^{1} \mathrm{H}$ nuclear magnetic resonance was 14 for the sample with a feed ratio of LLA to castor oil of 50. This value was relatively close to the value calculated from the feed ratio (degree of polymerization=16). Thus, the feed ratio was used to measure the molecular weight of the branched polymer in the evaluation of properties and plasticization effects. These data strongly suggest that all the hydroxyl groups of the castor oil reacted with lactide to produce the branched polymer.

The molecular weight of the polymer was determined by sizeexclusion chromatographic using polystyrene as a standard. The molecular weight increased linearly as a function of the feed ratio (see Supporting Information), suggesting that the molecular weight of branched poly(lactic acid) bearing a castor oil core can be controlled by the feed ratio of lactide to castor oil. The molecular weight distribution of the resulting polymer was between 1.6 and 2.1.

\section{Thermal properties of branched poly(lactic acid)}

The thermal properties of PLLA and branched poly(lactic acid) were evaluated using DSC. PLLA is a crystalline polymer with a glass transition temperature $\left(T_{\mathrm{g}}\right)$ and melting point $\left(T_{\mathrm{m}}\right)$ of 58 and $167^{\circ} \mathrm{C}$, 


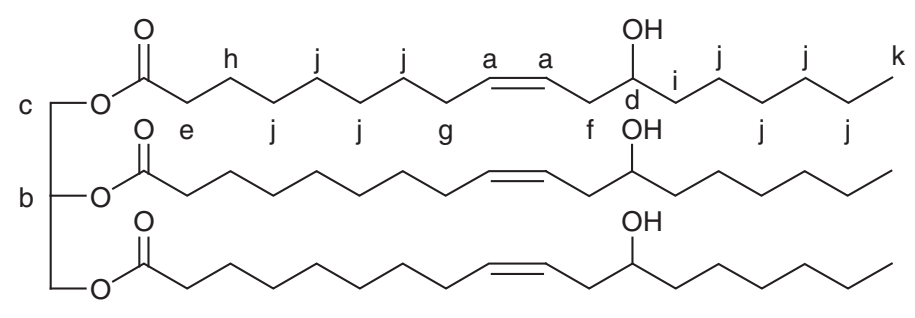

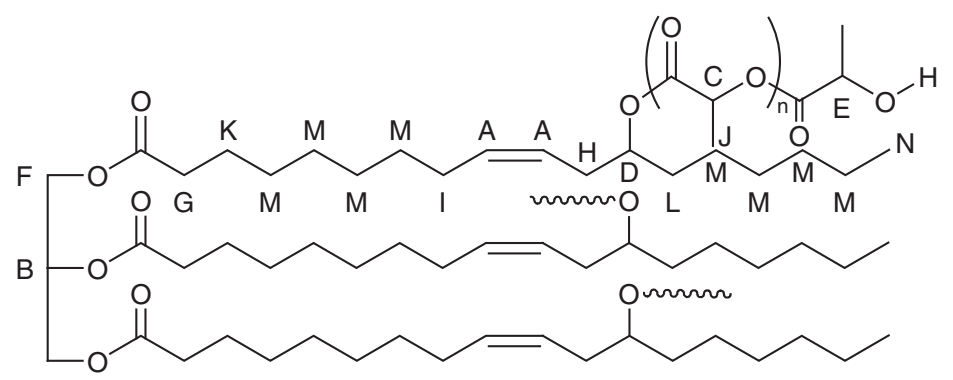

a

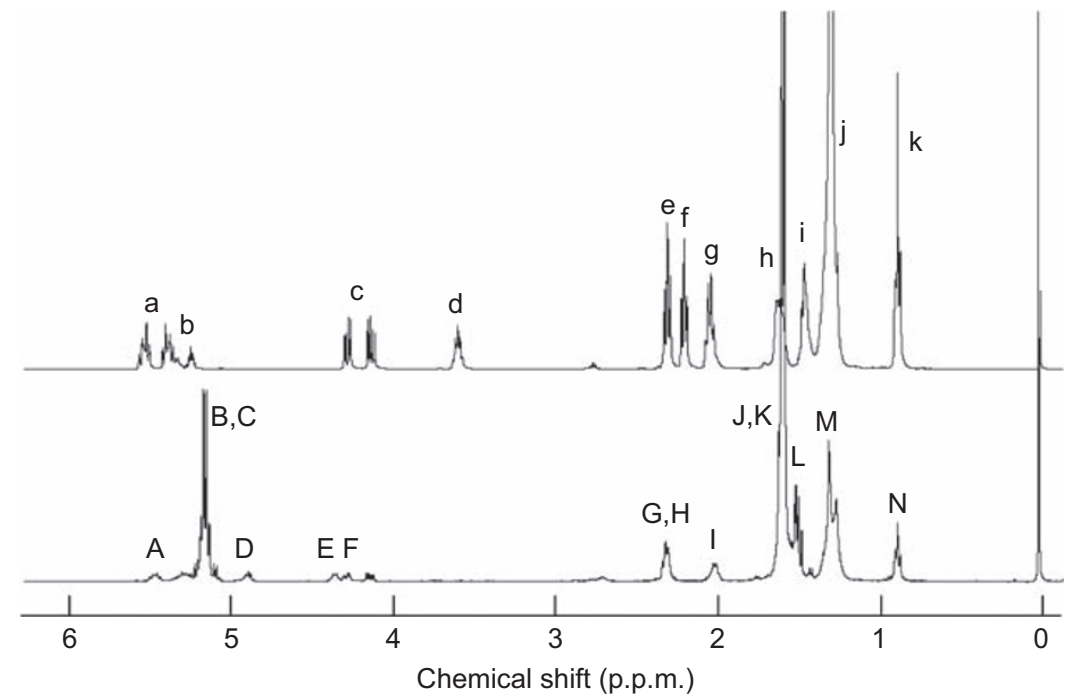

Figure $1^{1} \mathrm{H}$ nuclear magnetic resonance spectra of (a) castor oil and (b) branched poly(L-lactic acid) (L10).

respectively. For all samples, clear transitions at $T_{\mathrm{g}}$ and $T_{\mathrm{m}}$ were observed in the second heating scan. On the basis of the enthalpy of fusion of $100 \%$ crystallized PLLA $\left(93.7 \mathrm{~J} \mathrm{~g}^{-1}\right),{ }^{28-30}$ the crystallinity $\left(X_{\mathrm{c}}\right)$ of the branched polymer was calculated from the melting endotherm of the sample.

Figure 2 relates the feed ratio of LLA to castor oil, $T_{\mathrm{g}}, T_{\mathrm{m}}$ and $X_{\mathrm{c}}$. These values gradually increased with increasing feed ratio. The $T_{\mathrm{g}}$ and $T_{\mathrm{m}}$ of the branched polymer were lower than those of PLLA, and a large difference in $T_{\mathrm{g}}$ between the branched and linear polymers was found. Similar behaviors were observed for branched poly(lactic acid) bearing a polyglycidol core. ${ }^{15}$ The $X_{\mathrm{c}}$ value of the branched polymer was also lower than that of PLLA (45\%).

\section{Plasticization effect of branched poly(lactic acid)}

To evaluate the plasticization effect of the branched polymer, the blended film of the branched polymer and PLLA was prepared by hot pressing at $175^{\circ} \mathrm{C}$. Seven blended samples were used for the evaluation of the plasticization effect (Table 1). All the prepared samples were transparent, suggesting good miscibility of the branched polymer and PLLA (see Supporting Information). Strain-stress curves of PLLA and
PLLA/L50-blended (95:5 wt\%) films are shown in Figure 3. After the addition of the branched polymer, the strain at break was increased. Table 1 summarizes the results of the tensile testing of the blended films containing $5 \mathrm{wt} \%$ branched polymer with different feed ratios. The strain at break depended on the feed ratio (molecular weight) of the branched polymer, and the largest strain at break was found in L50. Interestingly, the tensile stress hardly changed with the addition of the branched polymer. The tensile stress has been shown to decrease with addition of low-molecular-weight plasticizer for PLLA. ${ }^{22-25}$

The effect of the content of the branched polymer (L20) on the mechanical properties of the blended film was examined (Figure 4). A content of $5 \mathrm{wt} \%$ of the branched polymer was sufficient for plasticization of PLLA. The strain at break decreased for the film containing $10 \mathrm{wt} \%$ branched polymer. For the reported plasticizers with low-molecular weight, more than $10 \mathrm{wt} \%$ was often necessary for plasticization of PLLA, and a substantial decrease in tensile strength resulted. ${ }^{22-25}$ On the other hand, a small amount of the present branched polymer was sufficient to plasticize PLLA without a decrease in tensile strength, although the strain at break was not as high as that of the reported plasticizers. 

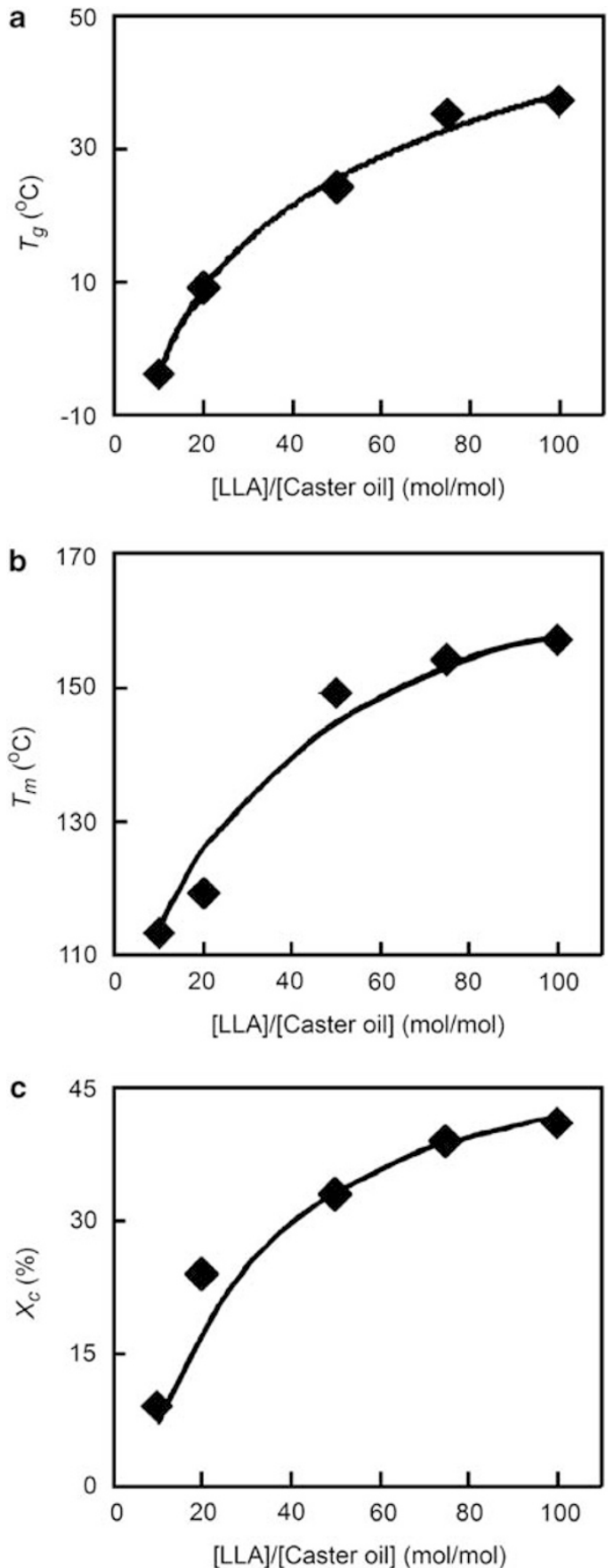

Figure 2 Relationships between the feed ratio of L-lactide to castor oil and (a) glass transition temperature $\left(T_{\mathrm{g}}\right)$, (b) melting point $\left(T_{\mathrm{m}}\right)$ and (c) crystallinity $\left(X_{C}\right)$ of branched poly(L-lactic acid).

Thermomechanical analysis has been reported to be useful in the evaluation of the initial elastic modulus of materials. ${ }^{30-33}$ Figure 5 shows strain-stress curves of PLLA and PLLA/L50-blended (95:5 wt\%) films. The initial elastic moduli of PLLA and the blended films were 1.8 and $1.6 \mathrm{GPa}$, respectively, indicating that the compliance was slightly improved by the addition of the branched polymer.

Thermal properties of blends of PLLA and branched poly(lactic acid) Figure 6 shows DSC curves in the second heating of PLLA and PLLA/ L50-blended (95:5 wt \%) films. With the addition of the branched
Table 1 Mechanical properties of PLLA/branched polymer film ${ }^{a}$

\begin{tabular}{lccccc}
\hline Code $^{\mathrm{b}}$ & Monomer & $\begin{array}{c}\text { Feed } \\
\text { ratio }^{\mathrm{c}}\end{array}$ & $\begin{array}{c}\text { Content } \\
(\text { wt\% })^{\mathrm{b}}\end{array}$ & $\begin{array}{c}\text { Tensile } \\
\text { strength (MPa) }\end{array}$ & $\begin{array}{c}\text { Strain at } \\
\text { break (\%) }\end{array}$ \\
\hline L20 & L-lactide & 20 & 1 & 50 & 38 \\
L20 & L-lactide & 20 & 3 & 49 & 44 \\
L20 & L-lactide & 20 & 5 & 45 & 48 \\
L20 & L-lactide & 20 & 10 & 44 & 27 \\
L50 & L-lactide & 50 & 5 & 43 & 62 \\
L100 & L-lactide & 100 & 5 & 43 & 49 \\
DL50 & D,L-lactide & 50 & 5 & 55 & 47 \\
- & - & - & 0 & $41^{\mathrm{d}}$ & $18^{\mathrm{d}}$ \\
\hline
\end{tabular}

Abbreviation: PLLA, poly(L-lactic acid)

aDetermined by tensile testing.

${ }^{b}$ Branched poly(lactic acid).

'Lactide/castor oil (molar ratio).

dData for PLLA.

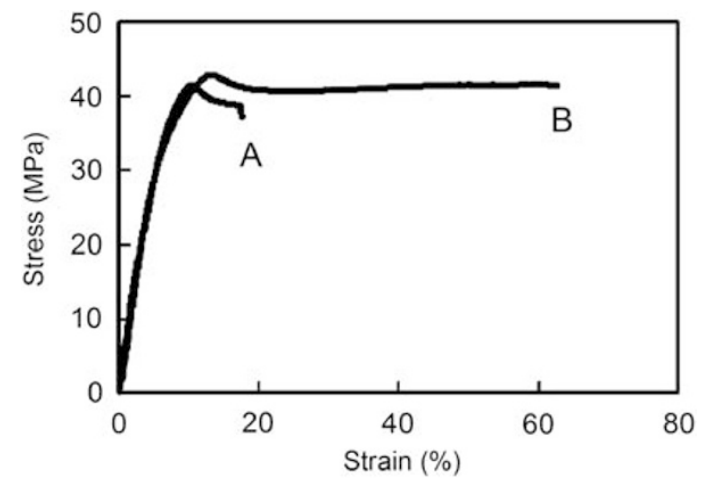

Figure 3 Strain-stress curves of (A) poly(L-lactic acid) (PLLA) and (B) PLLA/ L50 (95:5 wt\%) blended films.

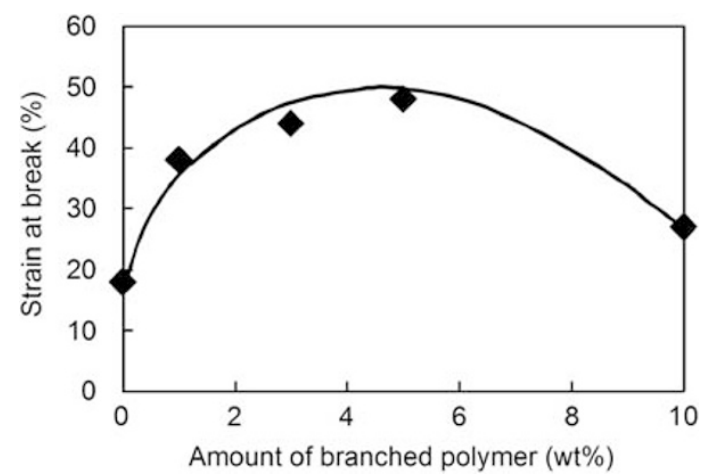

Figure 4 Effect of the content of the branched polymer on the strain at break of the blended films.

polymer, $T_{\mathrm{g}}$ and the crystallization temperature $\left(T_{\mathrm{c}}\right)$ decreased slightly. Table 2 summarizes the thermal properties of the blended films, evaluated by DSC. A gradual decrease of $T_{\mathrm{g}}$ and $T_{\mathrm{c}}$ as a function of the content of the branched polymer (L20) was observed. The thermal properties of the blended film also depended on the feed ratio. For $T_{\mathrm{g}}$ and $T_{\mathcal{c}}$, the difference between PLLA and the blend of L20 was larger than that of other branched polymers. The crystallinity of the blend scarcely changed compared with that of PLLA. The properties of the blended film containing branched poly(D,L-lactic acid) were similar to those of the branched PLLA, suggesting little effect of the stereochemistry of the branched chain. 


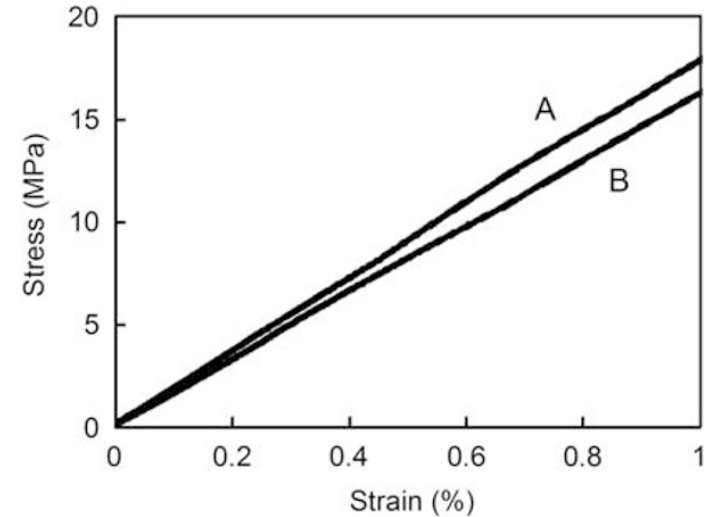

Figure 5 Initial elastic moduli of (A) poly(L-lactic acid) (PLLA) and (B) PLLA/L50 (95:5 wt\%) blended films.

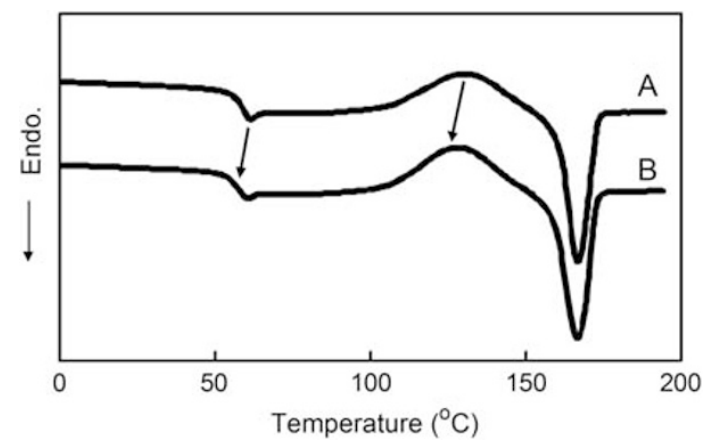

Figure 6 Differential scanning calorimetry traces of (A) poly(L-lactic acid) (PLLA) and (B) PLLA/L50 (95:5 wt\%) blended films.

Table 2 Thermal properties of PLLA/branched polymer filma

\begin{tabular}{lcccc}
\hline Code $^{\mathrm{b}}$ & Content $(w t \%)^{\mathrm{b}}$ & $T_{g}\left({ }^{\circ} \mathrm{C}\right)$ & $T_{c}\left({ }^{\circ} \mathrm{C}\right)$ & $T_{m}\left({ }^{\circ} \mathrm{C}\right)$ \\
\hline L20 & 1 & 54 & 129 & 167 \\
L20 & 3 & 54 & 124 & 166 \\
L20 & 5 & 49 & 119 & 168 \\
L20 & 10 & 48 & 118 & 163,169 \\
L50 & 5 & 53 & 128 & 167 \\
L100 & 5 & 54 & 128 & 167 \\
DL50 & 5 & 53 & 124 & 166 \\
- & 0 & $58^{\mathrm{c}}$ & $131^{\mathrm{c}}$ & $167^{\mathrm{c}}$ \\
\hline
\end{tabular}

Abbreviations: DSC, differential scanning calorimetry; PLLA, poly(L-lactic acid);

$T_{\mathrm{c}}$, crystallization temperature; $T_{\mathrm{g}}$, glass transition temperature; $T_{\mathrm{m}}$, melting point.

aDetermined by DSC.

Branched poly(lactic acid)

'Data for PLLA.

Figure 7 shows the temperature dependence of the storage modulus $\left(E^{\prime}\right)$ of PLLA and PLLA/L50 (95:5 wt\%), determined by dynamic mechanical analysis. $E^{\prime}$ abruptly decreased around $T_{\mathrm{g}}$, and then abruptly increased around $T_{\mathrm{c}}$. The $E^{\prime}$ of the blended film above $T_{\mathrm{c}}$ was lower than that of PLLA. A similar behavior was observed for the film sample of PLLA/DL50 (95:5 wt\%; data not shown).

The effect of the branched polymer on the crystalline morphology of PLLA was examined by polarized light microscopy. The sample was melted and then cooled to room temperature. The crystal of PLLA became smaller with the addition of the branched polymer (see Supporting Information), suggesting that the branched polymer

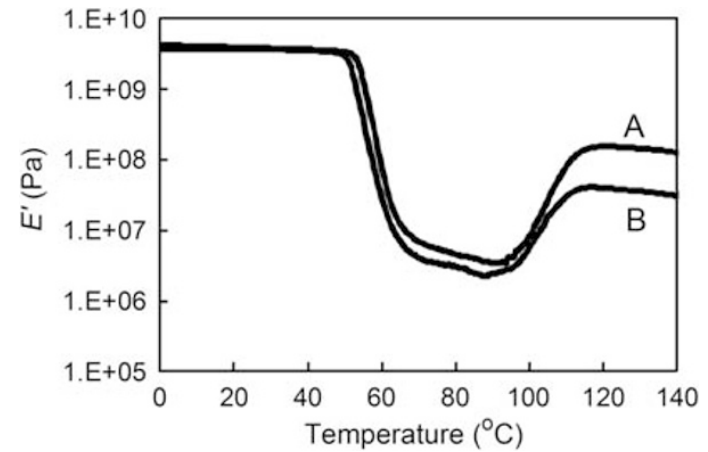

Figure 7 Temperature dependence of the storage modulus $\left(E^{\prime}\right)$ of $(A)$ poly (L-lactic acid) (PLLA) and (B) PLLA/L50 (95:5 wt\%) blended films.

suppresses the crystal growth of PLLA. The plasticizer effect of reported compounds with low-molecular weight is often attributed to a decrease in crystallinity. ${ }^{25}$ In contrast, the high plasticization effect of the present branched polymer might be due to the flexibility of the core structure of the branched polymer and the decreased crystal size of PLLA. This may lead to an increase of the strain at break without a change in the tensile strength and thermal properties of PLLA.

\section{CONCLUSION}

A new class of polymeric plasticizers was produced by ring-opening polymerization of lactide in the presence of castor oil. The molecular weight of the branched polymer could be controlled by the feed ratio of lactide to castor oil. $T_{\mathrm{g}}, T_{\mathrm{m}}$ and $X_{\mathrm{c}}$ increased as a function of the feed ratio, and these values were lower for the branched polymer than for PLLA. The blended film of PLLA and branched polymer, which was prepared by hot pressing at $175^{\circ} \mathrm{C}$, showed a good plasticization effect on PLLA. Only $5 \mathrm{wt} \%$ of the branched polymer was enough to plasticize PLLA. Although the strain at break of the blended film was not high, the tensile strength was scarcely changed by the addition of the branched polymer, indicating that the plasticized PLLA film retained the mechanical strength with a decrease in brittleness. $T_{\mathrm{g}}$ and $T_{\mathrm{c}}$ of PLLA were slightly lowered by the addition of the branched polymer. As the content of the branched polymer increased, a gradual decrease in these values was observed. Furthermore, the addition of the branched polymer to PLLA reduced the crystal size of PLLA. Some of these effects were specific for the present polymeric plasticizer, but were not observed for the reported plasticizers with low-molecular weight. In addition, the polymeric plasticizers, such as the branched polymer, might prevent the migration or volatilization of the plasticizer, leading to good stability over time.

Because the branched polymer consists of bio-based castor oil and lactic acid, the biomass content of the plasticized film containing the branched polymer was $100 \%$. Therefore, it is possible that the resulting branched polymer will greatly contribute to the reduction of greenhouse gas emissions compared with PLLA products containing commercially available petroleum-based additives. This study is highly significant for the molecular design of high-performance biobased products for industrial applications. Further studies on the applications of branched poly(lactic acid) are currently underway in our laboratory.

\section{ACKNOWLEDGEMENTS}

This study was partly supported by a Grant-in-Aid for Scientific Research from the Japan Society for the Promotion of Science (No. 21350124) and the New Energy and Industrial Technology Development Organization (NEDO) of Japan. 
1 Mecking, S. Nature or petrochemistry? -biologically degradable materials. Angew. Chem. Int. Ed. 43, 1078 (2004).

2 Mohanty, A. K., Misra, M. \& Hinrichsen, G. Biofibres, biodegradable polymers and biocomposites: an overview. Macromol. Mater. Eng. 276/277, 1 (2000).

3 Biermann, U., Friedt, W., Lang, S., Lühs, W., Machmüller, G., Metzger, J. O., Klaas, M. R., Schäfer, H. J. \& Schneider, M. P. New syntheses with oils and fats as renewable raw materials for the chemical industry. Angew. Chem. Int. Ed. 39, 2206 (2000).

4 Mutlu, H. \& Meier, M. A. R. Castor oil as a renewable resource for the chemical industry. Eur. J. Lipid Sci. Technol. 112, 10 (2010).

5 Yeganeh, H. \& Hojati-Talemi, P. Preparation and properties of novel biodegradable polyurethane networks based on castor oil and poly(ethylene glycol). Polym. Degrad. Stab. 92, 480 (2007).

6 Karak, N., Rana, S. \& Cho, J. W. Synthesis and characterization of castor-oil-modified hyperbranched polyurethanes. J. Appl. Polym. Sci. 112, 736 (2009).

7 Wang, H. J., Rong, M. Z., Zhang, M. Q., Hu, J., Chen, H. W. \& Czigány, T. Biodegradable foam plastics based on castor oil. Biomacromol. 9, 615 (2008).

8 Ebata, H., Toshima, K. \& Matsumura, S. Lipase-catalyzed synthesis and curing of highmolecular-weight polyricinoleate. Macromol. Biosci. 7, 798 (2007).

9 Slivniak, R. \& Domb, A. J. Lactic acid and ricinoleic acid based copolyesters. Macromolecules 38, 5545 (2005).

10 Sokolsky-Papkov, M. \& Domb, A. J. Stereoisomeric effect on in vitro drug release from injectable poly(lactic acid co castor oil) polyesters. Polym. Adv. Technol. 19, 671 (2008).

11 Drumright, R. E., Gruber, P. R. \& Henton, D.E. Polylactic acid technology. Adv. Mater. 12, 1841 (2000).

12 Tsuji, H. Poly(lactide) stereocomplexes: formation, structure, properties, degradation, and applications. Macromol. Biosci. 5, 569 (2005).

13 Gupta, B., Revagade, N. \& Hilborn, J. Poly(lactic acid) fiber: an overview. Prog. Polym. Sci. 32, 455 (2007).

14 Numata, K., Srivastava, R. K., Finne-Wistrand, A., Albertsson, A.- C., Doi, Y. \& Abe, H. Branched poly(lactide) synthesized by enzymatic polymerization: effects of molecular branches and stereochemistry on enzymatic degradation and alkaline hydrolysis. Biomacromol. 8, 3115 (2007).

15 Ouchi, T., Ichimura, S. \& Ohya, Y. Synthesis of branched poly(lactide) using polyglycidol and thermal, mechanical properties of its solution-cast film. Polymer 47, 429 (2006).

16 Biela, T., Duda, A., Pasch, H. \& Rode, K. Star-shaped poly(L-lactide)s with variable numbers of hydroxyl groups at polyester arms chain-ends and directly attached to the star-shaped core-controlled synthesis and characterization. J. Polym. Sci. Part A: Polym. Chem. 43, 6116 (2005).
17 Tsuji, H., Miyase, T., Tezuka, Y. \& Saha, S. K. Physical properties, crystallization, and spherulite growth of linear and 3-arm poly(L-lactide)s. Biomacromol. 6, 244 (2005).

$18 \mathrm{Kim}$, E. S., Kim, B. C. \& Kim, S. H. Structural effect of linear and star-shaped poly (L-lactic acid) on physical properties. J. Polym. Sci. Part B: Polym. Phys. 42, 939 (2004).

19 Pitet, L. M., Hait, S. B., Lanyk, T. J. \& Knauss, D. M. Linear and branched architectures from the polymerization of lactide with glycidol. Macromolecules 40, 2327 (2007).

20 Gottschalk, C. \& Frey, H. Hyperbranched polylactide copolymers. Macromolecules 39 , 1719 (2006).

21 Baiardo, M., Frisoni, G., Scandola, M., Rimelen, M., Lips, D., Ruffieux, K. \& Wintermantel, E. Thermal and mechanical properties of plasticized poly(L-lactic acid). J. Appl. Polym. Sci. 90, 1731 (2003).

22 Murariu, M., Ferreira, A. D. S., Alexandre, M. \& Dubois, P. Polylactide (PLA) designed with desired end-use properties: 1. PLA compositions with low molecular weight ester-like plasticizers and related performances. Polym. Adv. Technol. 19, 636 (2008).

23 Ljungberg, N. \& Wesslén, B. The effects of plasticizers on the dynamic mechanical and thermal properties of poly(lactic acid). J. Appl. Polym. Sci. 86, 1227 (2002).

24 Yeh, J.- T., Huang, C.- Y., Chai, W.- L. \& Chen, K.- N. Plasticized properties of poly(lactic acid) and triacetine blends. J. Appl. Polym. Sci. 112, 2757 (2009).

25 Ren, Z., Dong, L. \& Yang, Y. Dynamic mechanical and thermal properties of plasticized poly(lactic acid). J. Appl. Polym. Sci. 101, 1583 (2006)

26 Ljungberg, N. \& Wesslén, B. Preparation and properties of plasticized poly(lactic acid) films. Biomacromol. 6, 1789 (2005).

27 Kulinski, Z., Piorkowska, E., Gadzinowska, K. \& Stasiak, M. Plasticization of poly (L-lactide) with poly(propylene glycol). Biomacromol. 7, 2128 (2006).

28 Garlotta, D . A literature review of poly(lactic acid). J. Polym. Environ. 9, 63 (2001).

29 Fischer, E. W. Sterzel, H. J. \& Wegner, G. Investigation of the structure of solution grown crystals of lactide copolymers by means of chemicals reactions. Kolloid. Z. Z. Polym. 251, 980 (1973).

30 Cheng, S., Lau, K.-t., Liu, T., Zhao, Y., Lam, P.- M. \& Yin, Y. Mechanical and thermal properties of chicken feather fiber/PLA green composites. 40, 650 (2009).

31 Manich, A. M., Carilla, J., Miguel, R. A. L., Lucas, J. M., Franco, F. G. F., Montero, L. A. \& Cayuela, D. Thermal transitions of polylactide false-twist textured multifilaments determined by DSC and TMA. J. Therm. Anal. Calorim. 99, 723 (2010).

32 Liu, T.- Y., Lin, W.- C., Yang, M.- C. \& Chen, S.- Y. Miscibility, thermal characterization and crystallization of poly(L-lactide) and poly(tetramethylene adipate-co-terephthalate) blend membranes. Polymer 46, 12586 (2005).

33 Ozkoc, G. \& Kemaloglu, S. Morphology, biodegradability, mechanical, and thermal properties of nanocomposite films based on PLA and plasticized PLA. J. Appl. Polym. Sci. 114, 2481 (2009).

Supplementary Information accompanies the paper on Polymer Journal website (http://www.nature.com/pj) 